
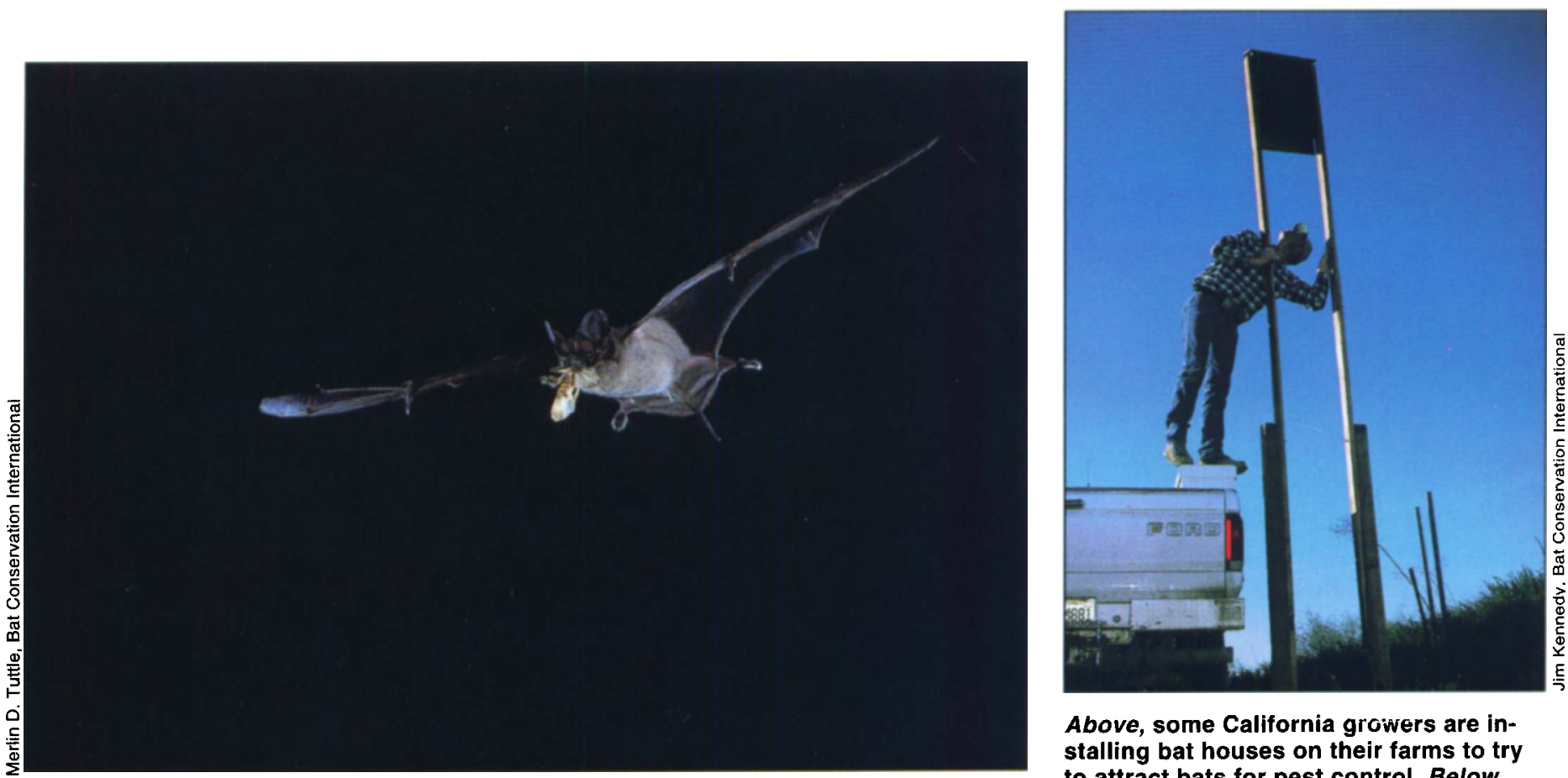

Above, some California growers are installing bat houses on their farms to try to attract bats for pest control. Below,

Mexican free-tailed bats, a common species in the Sacramento Valley, feed on a variety of insects including moths, water boatmen, beetles, flies, midges, mosquitoes and plant bugs.

\title{
Bats feed on crop pests in Sacramento Valley
}

\author{
Rachael Freeman Long a Tiffanie Simpson \\ Tzung-Su Ding \ Steve Heydon a Wilbur Reil
}

\author{
Food habits of Mexican free-tailed \\ bats and Yuma myotis bats were \\ examined in the Sacramento Val- \\ ley. Analyses of guano samples \\ indicated that Mexican free-tailed \\ and Yuma myotis bats fed on \\ moths, water boatmen, beetles, \\ flies, midges, mosquitoes and \\ plant bugs. The diet of Yuma \\ myotis bats tended to be diverse \\ early in the season, but more \\ uniform later on when they ate \\ more moths. In contrast, Mexican \\ free-tailed bats primarily fed on \\ midges, flies and mosquitoes \\ early in the season, then became \\ more generalized feeders later \\ on. These data demonstrate that \\ bats are beneficial as they feed \\ on insects that can be pests of \\ agriculture.
}

Bats are predators of night-time flying insects, including many that are agricultural pests (Tuttle 1988). For example, big brown bats in the Midwest favor cucumber beetles, June bugs, stinkbugs and leafhoppers (Whitaker 1995). Other species of bats primarily feed on moths, the larvae of which tend to be crop pests. For example, McCracken (1996) found that Mexican free-tailed bats feed extensively on migrating populations of corn earworm moths, a major pest of corn, tomatoes and beans.

In terms of numbers of insects consumed, a typical colony of 150 bats will eat more than a million insects each season (Whitaker 1995) and the 20 million bats in Bracken Cave, Texas, eat about 250 tons of insects nightly. It seems clear that bats potentially can help protect growers from agricultural pests, and a number of California growers are installing bat houses on their farms to try to attract bats for pest control (Tuttle and Hensley 1993).

Nonetheless, there are few data on the food habits of bats in California; therefore, we do not knuw their potential impact on pests in our area. We need to assess the diet of bats on a local level, to understand their role as predators in agricultural systems, because food habits vary with locality, time of year, species of bat, time of feeding and available insect prey.

The purpose of our research was to determine the food habits of Mexican free-tailed bats, Tadarida brasiliensis and Yuma myotis bats, Myotis yumanensis, in the Sacramento Valley. These two species commonly form colonies in our area. 


\section{Guano sampling}

We determined food habits of Mexican free-tailed-and Yuma myotis bats in Yolo County in 1995 by examining their fecal pellets. This method is a reliable way to assess what bats are feeding on, as all flying insects contain chitin, a substance mostly indigestible to bats. As a result, insect parts such as legs, wings and antennae can usually be identified to order, family and sometimes species. This technique is much less destructive than earlier methods that involved killing bats and looking at stomach contents. The disadvantage to this method is that a few soft-bodied insects may be too digested to identify in the samples.

A colony of Mexican free-tailed bats currently inhabits expansion joints in a freeway overpass located directly above a perennial stream that is surrounded by irrigated farmland. This is a large maternity colony with several thousand individuals. The Yuma myotis bats live in the folds of burlap sacks that hang in a rancher's barn, near irrigated and dryland farms. This colony is also a maternity colony, including several hundred individuals.

We collected approximately 20 fecal pellets from drop cloths placed below each colony about every 2 weeks from April, when the bats arrived, until September when they migrated out of the valley for the winter. Insofar as possible, we identified each food item and visually estimated its percentage volume in each pellet. Data were summarized by calculating the average percent volume of each insect group for each sample date. The frequency that bats fed on each insect group was determined by the number of pellets that contained a particular insect divided by the total number of pellets.

\section{Seasonal diet changes}

In April and May, about $85 \%$ of the Mexican free-tailed bat's diet consisted of flies, mosquitoes (Cyclicidae) and midges (Chironomidae) (fig. 1). From July until September, they became more generalized in their feeding habits as they fed on plant bugs including leafhoppers (Hemiptera), beetles including a few ground beetles (Carabidae), water boatmen (Corixidae), moths (Lepidoptera), and a few brown lacewings (Hemerobiidae).

Early in the season from April to June, Yuma myotis bats fed on a diversity of insects including water boatmen, moths, flies, mosquitoes, midges, beetles, plant bugs, moths and a few brown lacewings (fig. 2). By July, they started feeding on more moths, which accounted for $70 \%$ of their diet by September.

The frequency of insects found in the Mexican free-tailed and Yuma myotis bat diets show that they often select similar prey (figs. 3 and 4). One exception is with water boatmen; Yuma myotis bats primarily fed on these insects in April whereas Mexican freetailed bats fed on them in July. This difference in feeding habits is probably due to the temporal availability of these insects. Water boatmen are strong flyers and begin to disperse from water holes as they dry. This occurred earlier in the season near the Yuma myotis bat roost, as this colony is located in a dryland farming area.

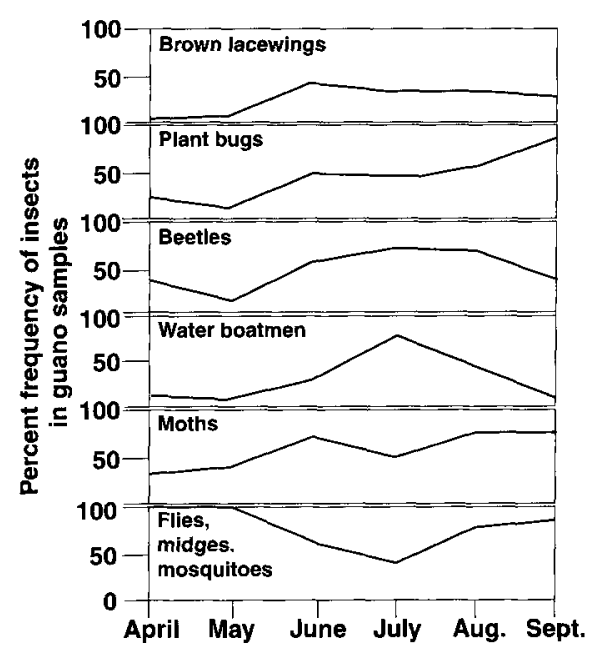

Fig. 3. Frequency of insects found in the Mexican free-tailed bat diet.

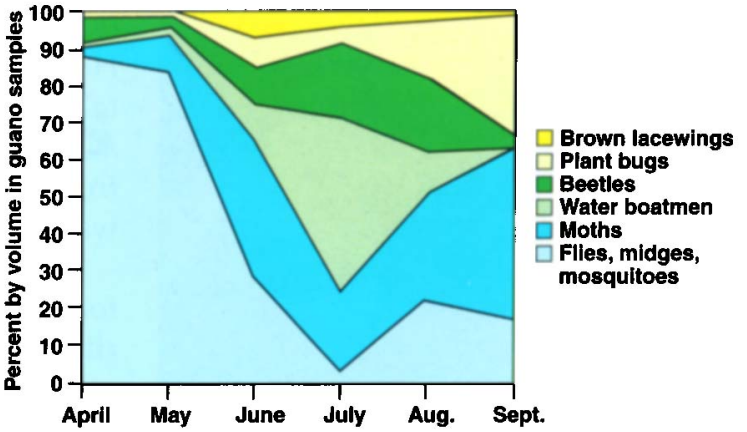

Fig. 1. Mexican free-tailed bat diet, as determined by the percent volume of insects found in guano pellets.

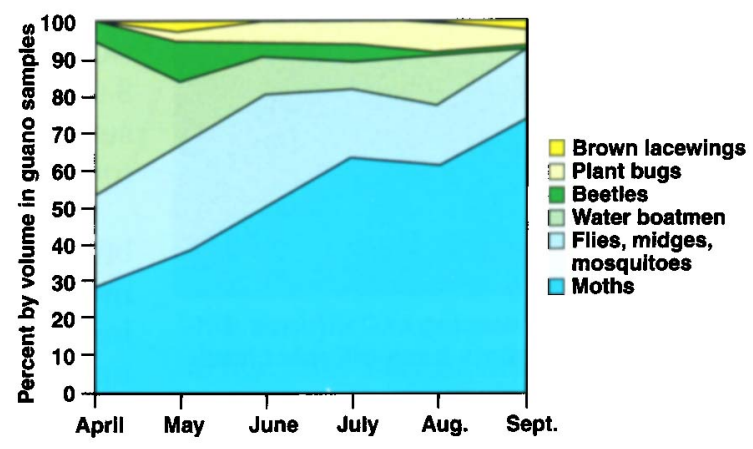

Fig. 2. Yuma myotis bat diet, as determined by the percent volume of insects found in guano pellets.

The Shannon-Weaver diversity index was used to measure and compare the variability of prey found in the Mexican free-tailed and Yuma myotis bat diet, based on percent volume (fig. 5). The higher the diversity index, the more general their diet becomes.

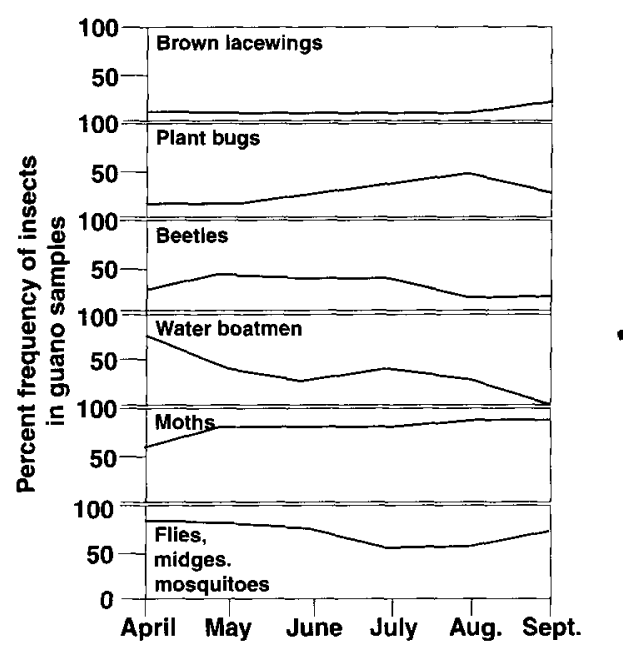

Fig. 4. Frequency of insects found in the Yuma myotis bat diet. 


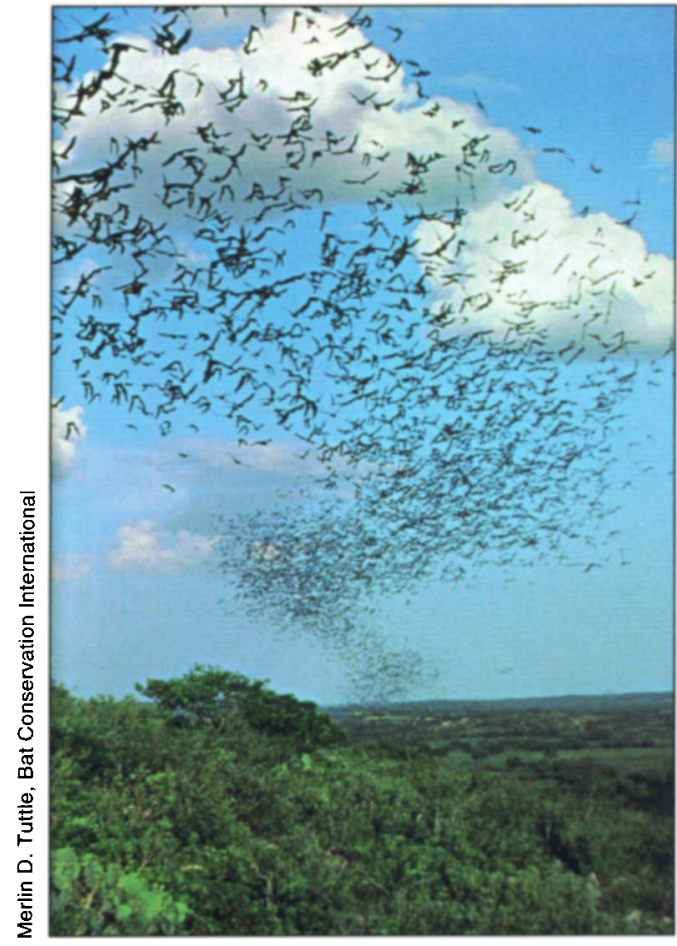

There are 26 bat species in California. Different species of bats have different feeding preferences.

The diet of Mexican free-tailed bats was more specific during April and May, then became more general by June. Conversely, the Yuma myotis bat diet tended to be more general early in the season, then more specific later in the season. All the insects that these bats fed on are common and abundant in California.

\section{Bats may reduce pests}

Research on Mexican free-tailed bats in other areas of the country also shows that these bats are generalist feeders, and that their feeding habits likely reflect changes in the distribu-

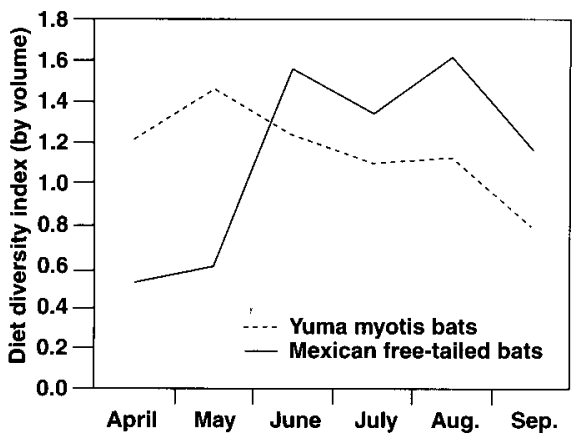

Fig. 5. Diet diversity index of Mexican freetailed bats and Yuma myotis bats. The higher the diversity index the more generalized the feeding habits. tion and abundance of available prey (Kunz et al. 1995; Whitaker 1996).

However, assessment of prey available to Mexican free-tailed bats is difficult as these bats can forage up to 30 miles from their roosts and at altitudes upwards of 2,400 feet.

Yuma myotis bats usually roost and forage near flowing water, and primarily feed on aquatic insects such as caddisflies, Trichoptera, and mayflies, Ephemeroptera (Brigham et al. 1992). They have also been shown to feed on Dipterans and moths as we found in our samples. We probably didn't find any caddisflies or mayflies in our samples as this colony is located about 8 miles from the nearest stream, presumably beyond the colony's normal foraging range.

Both species of bats also fed on brown lacewings and ground beetles, indicating they will feed on beneficial insects. However, these insects made up a small percentage of their diet. Many beneficial insects are diurnal or they have evolved ways to avoid predation by bats. For example, some adult green lacewings, Chrysopidae, which are most active at night, have "bat-detectors" on their wings and drop to the ground when they detect bat echolocations. They also emit a noxious odor, which makes them distasteful to predators. Brown lacewings have one of the lowest temperature thresholds of all beneficial insects; their peak activity occurs during early spring, before most bats have migrated into the Sacramento Valley. Although some people consider water boatmen to be beneficial because they eat a few mosquitoes, these insects primarily forage in bottom ooze, eating algae and microscopic organisms.

Based on our results, we know that bats in the Sacramento Valley feed on insects such as moths, beetles and plant bugs that are often agricultural pests. Potentially, they may help reduce insect infestations in crops by feeding on these pests. They may also protect crops from pests by "chasing" insects away with their echolocation calls. A number of moths, including cutworms, armyworms, and bollworms are sensitive to bat echolocation up to 130 feet away, and turn away or dive to the ground when ex- posed to pulsed sounds. This may be why some researchers saw a $50 \%$ reduction in damage to corn plots by corn borers when they broadcast batlike ultrasound over test plots. These moths are sensitive to bat echolocation calls, and probably began to avoid the plots.

Although bats are beneficial, they are often maligned. In some cases, important roosting habitat has been destroyed and whole colonies eliminated. Bats are slow to reproduce, with most California species having only one young per year; they are also vulnerable as many form colonies that can be easily disturbed or destroyed. As a result, we need to protect current colonies and develop ways to attract more bats to farms. Although bats alone will not control agricultural pests, they should be encouraged along with other naturally occurring predators, such as owls, raptors, and beneficial insects, to help diversify ecosystems and improve biocontrol of pests.

R.F. Long is UC Cooperative Extension Farm Advisor, Yolo and Solano counties; T. Simpson is graduate student, Entomology, UC Davis, T. Ding is graduate student, Agronomy, UC Davis, S. Heydon is Senior Museum Scientist, Bohart Museum, Entomology, UC Davis, and W. Reil is UC Cooperative Extension Farm Advisor, Yolo and Solano counties.

\section{References}

Brigham RM, Aldridge HDJN, Mackey RL. 1992. Variation in habitat use and prey selection by Yuma bats, Myotis yumanensis. J Mammal 73(3):640-5.

Kunz TH, Whitaker Jr JO, and Wadanoli MD. 1995. Dietary energetics of the insectivorous Mexican free-tailed bat (Tadarida brasiliensis) during pregnancy and lactation. Oecologia 101:407-15.

McCracken, G.F 1996. Bats aloft: A study of high-altitude feeding. Bats 14(3):7-10.

Tuttle MD. 1988. America's Neighborhood Bats. University of Texas Press, Austin, Texas.

Tuttle MD, Hensley DL. 1993. The Bat House Builder's Handbook. University of Texas Press, Austin, Texas.

Whitaker Jr JO. 1995. Food of the big brown bat Eptesicus fuscus from maternity colonies in Indiana and Illinois. Am Midl Nat 134:346-60.

Whitaker Jr JO. 1996. Dietary variation in the Mexican free-tailed bat (Tadarida brasiliensis mexicana). $\mathrm{J}$ of Mammal 77(3)716-24. 